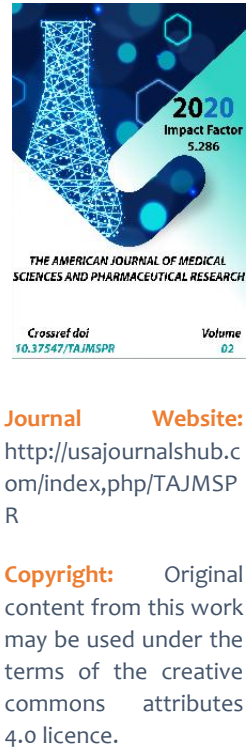

\title{
Analysis Of Approaches To Psychological Correction Of Adolescent Behavior In Crisis Situations And Techniques Of Its Organization
}

\author{
Tukhtakhon Gaynazarovna Suleymanova \\ Senior Teacher At The Department Of "General Psychology" Of Andizhan State University, \\ Candidate Of Psychological Sciences (Phd), Andizhan Region, Republic Of Uzbekistan
}

\section{ABSTRACT}

The article analyzes psychocorrectional measures carried out with adolescents in crisis situations, and an analysis of approaches to their organization.

\section{KEYWORDS}

Attitude, stress, adaptation, psychocorrection of emotional burnout, diagnostics, crisis, individual approach.

\section{INTRODUCTION}

In the context of political instability and economic crisis, the escalation of sociopsychological tensions, the work of practical psychologists, aimed at the widespread application of methods and techniques of psychological diagnosis of adolescent behavior in crisis, is becoming increasingly important. The term "correctio" means partial correction or modification. Psychological correction is a set of measures aimed at eliminating the shortcomings in the psyche, behavior, which are not organic in nature, or which have arisen in the early stages of life and have not become stable, using methods and means of psychological influence [11, p.6]. Thus, the purpose of psychological correction 
is to normalize the mental performance of the person, to create optimal conditions for the person to function, based on the requirements of society, before the mental disorders reach a painful level.

\section{METHODS}

\section{Psychological correction is characterized by:}

- Impossibility to postpone psychological help;

- Aimed at identifying and correcting incompatible psychological attitudes that lead to the formation of crisis situations in the person;

- To search for and implement previously untested ways of resolving current interpersonal conflicts, which increase the level of socio-psychological flexibility, as well as ensure the stability and personal growth of the individual. There are several forms and stages of psychological diagnosis and correction [15]. There are usually three main stages:

- psychological support;

- psychological intervention;

- Improving the level of socio-psychological adaptation.

There are also several forms and stages of psychological diagnosis and correction [8].

Usually its three main stages are distinguished:

- Establishing psychological communication;

- Explain the feeling of danger in times of crisis and stress;

- Mobilization of adaptive behavioral problem-solving skills;

- Conclusion of a contract at will.

\section{RESULTS AND DISCUSSIONS}

The first stage is the establishment of a psychological connection, which requires the adolescent to listen kindly, patiently, without suspicion and criticism. It ensures that the psychologist is accepted as a person with deep knowledge, understanding, sensitivity and trustworthiness in the field of psychological diagnosis and correction, especially in the problems of adolescents, to be able to provide practical assistance in solving adolescent problems should.

The second stage is the disclosure of the emotion that caused the crisis, which takes place in the context of the adolescent's unconditional acceptance, increasing his or her self-awareness. Listening kindly effectively reduces tension by making it easier to respond to the emotions that are being suppressed by the adolescent.

The third stage is carried out by mobilizing the adaptive skills of behavior to solve problems, activating past successes in areas important to man, increasing his self-esteem, confidence in his ability to solve the crisis.

The fourth stage is the conclusion of a contract, its expression in terms understandable to the adolescent, psychological diagnosis and correction with him, the timing of its implementation, sharing the results of joint work, independent control of his suicidal tendencies, as well as response to decisions and their implementation an agreement to grant.

It is here that the psychologist's mediation between other close people, which is important for the adolescent in establishing social relationships, is also agreed upon. Supportive tasks, the second stage of psychological diagnosis and correction, are 
considered to be performed only if the main affective disorders, which significantly reduce the activity of dangerous tendencies, allow the transition to cognitive reconstruction, which is carried out in the stage of psychological intervention.

The second stage - psychological intervention identifies the reconstruction (reconstruction) of the damaged micro-social sphere of the adolescent as its goal. This stage also consists of several periods:

- Consider previously untested ways to solve the problem;

- Identification of incompatible psychological attitudes that hinder the optimal ways to resolve the crisis;

- Correction of incompatible psychological attitudes;

- Activation of therapeutic facilities.

Considering untested ways of dealing with a problem involves first and foremost looking for people around you who can facilitate a person's microsocial resilience, forming a new high-value relationship that he or she needs. Identifying and correcting incompatible psychological attitudes is critical for the adolescent. At the same time, it is important to find an idea that this or that value is more important than one's own life, and on this basis to reduce the priority value at the expense of the actualization of negative emotional factors.

The third, final stage of psychological diagnosis and correction consists of raising the level of adaptation, which also consists of several stages:

- Development of self-control skills in relation to incompatible psychological attitudes;
- Expanding the scope of social support through the involvement of important people in the adolescent micro-social environment in the work of psychocorrection.

The period of adaptive skills training begins when the adolescent decides to change his or her position in relation to the conflict. At this stage, new ways of solving the problem will be tested and strengthened. This involves the correction of a number of incompatible personal traits, such as the need for excessive psycho-emotional interactions, underdevelopment of the professional field, low ability to compensate for it in a state of frustration $[5,7,12]$.

The general principles of working with adolescents in a crisis situation are as follows: $[12,14]$.

- Empathetic, intense-emotional kindness from the first moment, the formation of an informal attitude to the client;

- To allow the teenager's desires, fears and worries to be eliminated;

- Activation of opportunities;

- Compliance with anonymity requirements.

- The main tasks of the first interview should be:

- Reduction of emotional tension;

- Blocking the emotions that led to the crisis;

- To mobilize the adolescent to overcome difficult situations;

- Cases of possible psychological trauma in the process of this crisis and preparation for an adequate response to them;

- To strengthen the motivation of the adolescent to receive further psychological help, focusing part of the adolescent's attention from situational problems to internal problems. 
The difficulty in this process is manifested in the fact that in the relatively short-term psychological diagnosis and correction process, the adolescent must be highly motivated. Adolescents in crisis situations, on the other hand, are often less able to communicate emotionally and have no motivation at all $[12,13,14]$.

That is why the first meeting and conversation with a teenager is important for both him and the psychologist. During the implementation of psychological diagnosis and correction in adolescents, it is important to comprehensively analyze the social factors that lead to a crisis situation, accept the adolescent, understand and motivate him to further changes. The teenager wants to get out of the crisis, but "does not want to accept" the help offered.

All aspects of the psychological methods during the first conversation are aimed at creating the motivation for further changes in it: [14].

The first method is to enhance personal identification. At this point, it is important to identify the socio-demographic data of the adolescent and to verbally describe the information about his age, profession, family status. This helps to overcome the disturbances in the identity of the person expressed, especially during situational reactions.

The second method is to systematize the situation. It is important to establish the sequence of events that led to the crisis situation.

The third method is to overcome the urgency of the situation. In many cases, an awkward situation is perceived by the adolescent as the last, most acute situation that occurs only in him as a result of his personal shortcomings and wrongdoing. But the important task is to warn carefully and politely that such situations also occur in the lives of many people.

The fourth method is to get into the context. An awkward situation is perceived by the person as an unexpected, insurmountable, hopeless situation. But by revealing its structure and dynamics, we help the adolescent to understand that this situation has been formed for a long time, that it is related to certain events in the way of life that have already lost their significance, and that it can be changed.

The fifth method is to relieve tension. Often, the current situation seems to need to be addressed immediately for the adolescent. In this case, it is necessary to say that he has time to think carefully and make a decision. In the course of the conversation, it is often clear that a similarly tense situation with the teenager has occurred before, but he has managed to find a way to overcome it. At this point, it is important to determine the reasons why the adolescent is no longer able to take advantage of these opportunities. It is also important to gather complete information about loved ones who are not involved in the situation. Because often it is this first group of people - relatives, friends, colleagues - who are the source of support that can help the teenager to overcome this crisis.

1. The order of the psychologist's work with adolescents for a long time was as follows $[3,4]$ :

On the basis of the first interview, the psychologist determines the scope of psychodiagnostic measures in collaboration with the psychiatrist or individually: these can be personality research or pathopsychological methods. 
At the first stage after the first or second meeting, on the basis of the psychodiagnostic conclusion, the doctor together with the psychologist decides on the expediency of conducting psychocorrectional measures. If correction is recommended, the psychologist and psychiatrist will jointly determine its purpose, timing, and methods, as well as the number of appointments. Of course, the effectiveness of psychological diagnosis and correction depends not only on the choice of some method of adequate exposure to this form of adolescent behavior, but also on the degree of importance of the traumatic situation for the adolescent, crisis personality traits, emotionally close people supporting the adolescent. it is important to establish warm emotional connections with each other and to be able to focus these people's attention on solving adolescent problems.

In the second stage, it is appropriate to create a general plan of activities that can be expressed by the phrase "from general to specific (specific), from specific to general" when the psychologist conducts direct activities consisting of an average of two meetings per week for 3-5 weeks.

The second stage conditionally consists of three stages:

- The stage of finding opportunities;

- Increase the overall tone;

- Strengthen the adolescent's ability to adequately assess the world around them and their confidence in qualified care. In general, the second stage gives the adolescent the strength and desire to move on to solving specific problems and tasks around them and convinces them to achieve relatively large ideas and goals in terms of their scope and importance in specific situational situations. Allows the adolescent to reconsider their life values.

The third, final stage involves re-conducting certain diagnostic tests and interpreting the results positively by a psychologist.

Foreign psychologist O. Determining the level of crisis using Kerinberg's experience in diagnostic-correctional work should highlight a systematic approach to the psychological diagnosis of adolescent suicidal behavior, including a comprehensive clinical interview with the adolescent $[9,10]$. On the basis of clinical and psychological data it is possible to determine the course of psychological correction and prevention, the immediate task of which is to identify and resolve conflicts of personality using modern methods in accordance with the personality traits of the individual and the behavioral model of suicide. Psychological correction is selected in accordance with the purposes of application. Psychological correction in the process of dealing with crisis situations is the optimization, correction and normalization of certain mental functions of a person, the deviation of his individual-psychological characteristics from the optimal level [16]. There are five types of psychological correction strategies [2]:

- Psychological correction of specific mental function and components of the psyche;

- Demonstration of the effect of psychological correction or vice versa strategy;

- Psychological correction involved in the family or focused on individuality;

- Psychological correction in the form of individual or group training;

- Psychological correction, which is a component of clinical psychotherapy in the complex treatment of 
neuropsychiatric disorders or the main and leading method of psychological influence on a person with social adaptation and behavioral disorders. Optimal skills development occurs during trainings, and the most popular among them are autotraining, logotherapy, movement therapy, existential, NLP, psychodrama, art therapy, transactional analysis, and more.

The advantage of individual psychological correction is that it provides confidentiality and is more productive than group correction in its outcome. It is also necessary to conduct an individual correctional course in the early stages of a suicide attempt. The following cases of adolescence were an indication for the application of individual psychological correction:

- Strong anxiety;

- Stagnation or hyperactivity;

- Lack of self-confidence;

- Behavioral deviations;

- Unfounded fear;

- Insufficient self-awareness;

- Loss of purpose and meaning in life.

At the heart of the method lies the existentialhumanistic direction, in which there is free will, a conscious responsibility to form one's own inner world, to choose one's own way of life. In such an approach, the goal of correction is to convey to the human mind the content he or she wants to dedicate to his or her life.

The main concepts and situations used in this approach are: dialogue based on emotional intimacy, meeting, experience, feeling, authenticity (authenticity, conformity), adolescent personality activation, vital values, existence in the world, events (life situations), life, phenomenological world and others
$[1,7,12]$. The main purpose of applying these situations is to help the teenager to find meaning in life, to understand personal freedom, responsibility, to discover their potential and opportunities as a person in the process of full communication. At the same time, it is an important task to unconditionally recognize the life of the adolescent, his destiny, which is undoubtedly important, a unique value of his existence [15]. The ultimate goal is the transformation of the cognitive sphere and the formation of personal characteristics such as motives, needs, interests and desires, which allow to meet the necessary needs of the adolescent, to successfully resolve conflicts in the context of socio-psychological adaptation.

Individual, family, group forms are used in the implementation of psychological correction. Among the practical methods recommended in the literature, the following can be distinguished:

- Rational, cognitive and hypnosuggestive psychological correction, autogenic training and group discussion [6];

- Cognitive-behavioral correction of the transpersonal element, which supports the possibility of changes in the state of perception [8].

\section{CONCLUSION}

Thus, the forms of correctional work aimed at helping adolescents in a state of sociopsychological maladaptation, which occurs in response to acute stress, are not considered logically sufficient as a set of psychological methods and techniques designed primarily to prevent crises. Therefore, it is necessary to clarify the choice of diagnostic methods (tests, questionnaires, questionnaires) that can provide comprehensive information about the personality of the adolescent in a short 
period of time, the causes of crisis situations, the relatively effective implementation of psychological correction in adolescents. "Targets" are required. In this regard, in the implementation of diagnostic and correctional work with suicidal adolescents, it is advisable to use a number of foreign approaches and methods of foreign psychologists and suicidologists, adapted to local conditions.

\section{REFERENCES}

1. Art therapy / Comp. and total. Ed. A.I. Kopytina. - SPb.: Peter, 2001.

2. Antropov Yu.S., Shevchenko Yu.V. Psychosomatic disorders. -M.: Publishing house "Institute of psychotherapy", 1999. $-504 \mathrm{p}$.

3. Aivi A., Ivy M. Psychological counseling and psychotherapy. -M.: Scientificproduction publishing house of Lyubertsy, 1999. - $487 \mathrm{p}$.

4. Bubnov V.G., Bubnova N.V. How to prevent suicide. - M.: Publishing house "Halo", 1994. - 15 p.

5. Gilinsky Ya.I., Afanfsyev V.S. Sociology of deviant (deviant) behavior. Textbook. allowance. - SPb: SPb branch of IS RAS, 1993 - $248 \mathrm{p}$.

6. Isaev D.D. Psychosexual development and its deviations // Psychosomatic medicine for children. - SPb: Special literature, 1996 -p. 215 - 239.

7. Chestnut G.I., Sadok B.J. Clinical Psychiatry, V 2v. T. 1. Per. from English - M $\therefore$ Medicine, 1994 .- 672 p. 88 Lesin A.U. Psychodiagnostics and personality correction. - SPb .: Publishing house EKSMO-press, 2001.- 316 p.
8. Kozlov V. Intensive integrative psychotechnology. Theory. Practice. Experiment. M., 1998.

9. Kernberg O. Aggression in personality disorders. M .: Independent firm "Class", 1998. - $568 \mathrm{p}$.

10. Kernberg O. Severe personality disorders. Psychotherapy strategies / Per, with anl. M.I. Blockage of ova. - M .: Independent firm "Class", 2001.-464 p.

11. Polischuk Yu.I. On the so-called nonpathological situational reactions // Review of Psychiatry and Medical Psychology. V.M. Bekhterev. - 1993. - No. 3. - p. 156-158.

12. Lesin A.U. Psychodiagnostics and personality correction. - SPb.: Publishing house EKSMO-press, 2001.- 316 p.

13. Leontiev A.N. Lectures on general psychology. M .:"Sense”, 2000.

14. Osipova A. Introduction to psychocorrection. Voronezh, 2000. - 320 p.

15. Slavgorod Y.M. Clinical dynamics and therapy of mental disorders in adolescent girls in the post-suicidal period: Dissertation abstract for the degree of candidate of medical sciences. - M., 2000 .$23 \mathrm{p}$.

16. Eidemiller E.G., Yustitsky V.V. Family psychotherapy.-Psychology and psychotherapy of the family, - 3rd ed. SPb.: Peter, 2001 .656 p. 